\title{
SENSITIVITY ANALYSIS OF TANGENTIAL DIGGING FORCES OF THE BUCKET WHEEL EXCAVATOR SCHRS 1320 FOR DIFFERENT TERRACES
}

\author{
Jakub Gottvald $^{1}$, Zdeněk Kala ${ }^{2}$ \\ ${ }^{1}$ VÍTKOVICE ÚAM, Inc., Mezírka 775/1, 60200 Brno, Czech Republic \\ ${ }^{2}$ Institute of Structural Mechanics, Faculty of Civil Engineering, Brno University of Technology, \\ Veveři Str. 95, 60200 Brno, Czech Republic \\ E-mails: ${ }^{1} j a k u b @ g o t t v a l d . e u ;{ }^{2} k a l a . z @ f c e . v u t b r . c z$ (corresponding author) \\ Received 24 Feb. 2012; accepted 20 Apr. 2012
}

\begin{abstract}
Researches in the field of economy of control of mining processes of minerals are continually met with a number of unsolved and newly arising problems. New deposits of brown coal are located at greater depths than before and are more difficult to mine. Problems in the field of rock mining stem from the greater diversity of rocks in mining, and it results in more difficult mining conditions. On the other hand, even greater demands are made to decrease the economic demand of mining. Current research is aimed at the most optimal utilization of energy provided on the bucket wheel of excavators, such that the energy demand of the mining process decreases, whilst preserving maximum performance. These requirements place greater demands on the precision of planning of mining and maximum economic efficiency. The presented article illustrates the possibilities of the utilization of Sobol sensitivity analysis during the investigation of the influence of the parameters of mining processes on tangential digging forces. Analyses are carried out for the mining process of bucket wheel excavator SchRs 1320. For purposes of the study, detailed measurements of operational parameters were performed on the excavator during a whole work cycle.
\end{abstract}

Keywords: bucket wheel excavator, sensitivity analysis, tangential digging force, SchRs 1320, measurement, probability, efficiency.

\section{Introduction}

Maximum performance with minimum energy consumption, which presents contradictory demands that cannot be satisfied simultaneously, is required for each working machine. It is however possible to optimize the working activity of the machinery and to find the most optimal working conditions which are a compromise of both contradictory requirements.

Current researches in the field of mining technology are aimed at the optimization of the energy demand of mining, and at the optimization of maintenance and operation of mining technology. Operators of mining technology focus mainly on the effective utilization of energy in the mining of coal. Proper choice of mining approach can significantly increase the efficiency of bucket wheel excavators. Savings are also made on the energy necessary for mining of a given block, and mining time is also reduced significantly. This has a positive influence on the resulting price of the mined mineral.

The issue is topical in the Czech Republic but also elsewhere in the world due to the fact that easily accessible deposits of brown coal have mostly been mined and at present coal is mined in locations with very hard overburden and more frequently occurring sandstone bands. In the Czech Republic at present, mining is being performed in the location of Severočeské doly (North-
Bohemian pits) in places that were considered, in the 50's of the last century, as not-mineable by continuous mining. This all leads to significantly higher dynamic loading of mining equipment. A secondary effect stemming from worsened geological conditions is increased strain of utilized mining machinery. The cutting teeth wear out faster and must be exchanged more frequently. Shutdowns of machinery necessary for replacements increase costs of the mined coal once again. However, non-replacement of cutting teeth manifests itself as increased vibrations of the machinery during mining. This increased strain may lead to fatigue cracks on the bearing steel parts of the machinery which may further lead to serious damage of machinery (Bošnjak et al. 2010, 2011; Rusiński et al. 2010a).

In practice, the influence of digging forces on the vibration of bucket wheel excavator (BWE) and bearing steel structures is frequently analysed. Critical points the damage of which due to aging could lead to fatal consequences are determined numerically and experimentally (Bošnjak et al. 2009a; Rusiński et al. 2010b). The degree of vibration is determined and the possibility of resonance of frequency of mining forces with the natural frequencies of the machinery is examined (Gottvald 2010). Analyses of material properties of steel are performed (Melcher et al. 2004; Kala et al. 2009). Parallel attention is paid to better understanding of 
structural safety and reliability (Kala 2007, 2008; Kowal 2011; Radoń 2011; Karmazínová et al. 2009; Kala et al. 2010). Current research is aimed mainly at nonlinear analysis of the coupling systems (e.g., Melcher et al. 2009; J. Králik, J. Králik 2009; Juozapaitis et al. 2010; Sandovič et al. 2011) and advanced models for solving coupled safety problems (e.g., Liaudanskiene et al. 2012; Jiang et al. 2012; Turskis et al. 2012). Let us note that relatively sufficient statistical information is provided for the material characteristics of steel members in comparison to other related branches (e.g., Amšiejus et al. 2009, 2010; Lashgari et al. 2011).

Despite all maintenance efforts of machinery, breakdown of mining technology is not rare (Bošnjak et al. 2009b). It is usually the case of accidents occurring as a result of production errors or the design of unsuitable structural modifications. We often encounter breakdown occurring as a result of wear of rotational parts of the machinery (Savković et al. 2011). Another example is breakdown due to extreme loading, that was not taken into consideration during design (Gottvald 2011). All these undesirable effects are reflected in the final price of the mined coal. As a result, great emphasis is put on the correct planning of mining, such that operational costs are within a tolerable level.

Through optimal design of the mining parts of the BWE, we can minimize the energy required for mining and decrease vibrations of machinery evoked by the mining process. Problems of optimization of BWEs are specific, however we can use a number of advanced optimization approaches (Venskus et al. 2010; Sušinskas et al. 2011; Torno et al. 2011; Zavadskas et al. 2011). The optimal design of the bucket wheel and its motors requires the correct knowledge of the size of digging forces acting on the buckets. It is apparent that the size of digging forces is dependent on the properties of the mined material, and on the construction of the bucket wheel. These are parameters that we cannot influence, or rather can only in the course of design. During mining we can however choose the size of the mining block, which determines the volume of the actual mined overburden and also the amount of energy required for its cutting. We are thus able to satisfy both requirements through optimal setting.

Extensive studies examining the most appropriate ratios of the cutting depth and cutting width on the terrace have been carried out (Vladimirov et al. 1968; Durst, Vogt 1986; Fries et al. 2010). Conditions of when and how to increase or decrease the horizontal speed of bucket wheel boom, such that the ratio of cutting depth and width is optimal and constant if possible, were set.

Results of sensitivity analyses of parameters having an influence on the resulting size of the digging force are presented in the article. Obtained conclusions may be used for subsequent optimization of the mining process. Sobol decomposition was applied as a method for global sensitivity analysis (Saltelli et al. 2004). An analytical approach of the evaluation of the total tangential digging force based on the power of the motor, parameters of the mining block and properties of overburden is presented in the article. Probabilistic characteristics of considered random variables were evaluated from measurements during mining with BWE SchRs 1320, in the opencast mine Doly Nástup Tušimice, Czech Republic.

\section{Introduction of BWE SchRS 1320}

BWE SchRs 1320 (in accurate description SchRs $1320 / 4 \times 30$, where $4 \times 30$ is the depth and height reach of the bucket wheel boom) is operated at the opencast mine Doly Nástup Tušimice, Czech Republic. The main supplier of the BWE was the Prodeco Inc. in cooperation with the German company TryssenKrupp. The BWE was put into operation in 2006.

BWE SchRs 1320 is conceived as an excavator with non-telescopic bucket wheel boom. Movement of the excavator is facilitated by crawlers. The theoretical capacity of the excavator is $5500 \mathrm{~m}^{3}$ of overburden per hour. The excavator is approx. $100 \mathrm{~m}$ long and approx. $60 \mathrm{~m}$ high. Together with the loading unit and connecting bridge, it weighs 4193 tonnes. The diameter of the bucket wheel including cutting teeth, which are 26 in number, is $12.5 \mathrm{~m}$.

An overall view of the BWE SchRs 1320 is presented in Fig. 1.

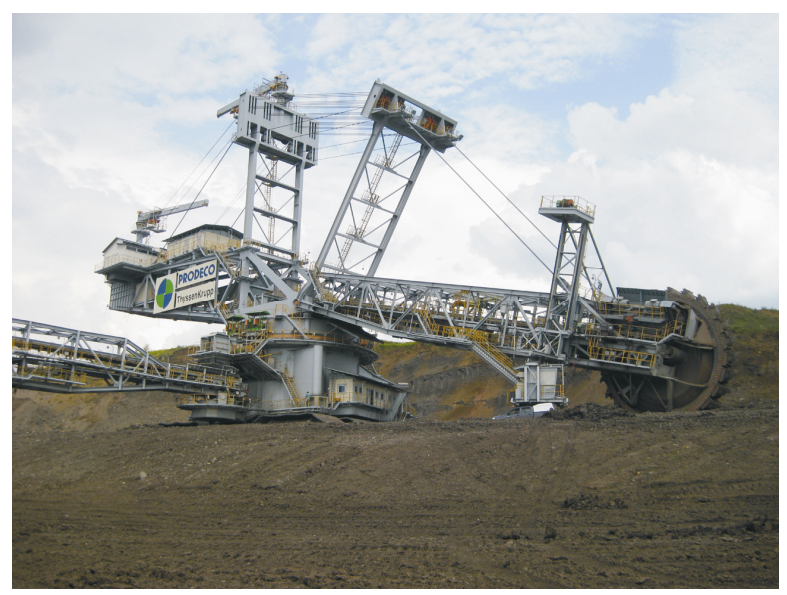

Fig. 1. Overall view of bucket wheel excavator SchRs 1320

\section{Calculation of tangential digging force}

As it already was mentioned, the analytic calculation of the total tangential digging force is evaluated from the input power of bucket wheel motors, from the parameters of the mining block and properties of overburden. The tangential digging force $F_{\text {grges }}$ is expressed as the ratio of the power $P_{g r}$ required in overcoming the tangential component of digging resistance to the angular velocity of the bucket wheel $\omega$ and bucket wheel radius $R_{k}$. The whole ratio is multiplied by the efficiency of the digging process $\eta_{\text {grges }}$ :

$$
F_{g r g e s}=\frac{P_{g r} \cdot \eta_{g r g e s}}{\omega \cdot R_{k}} .
$$

Power $P_{g r}$ is calculated from the total power of driving motors of the bucket wheel:

$$
P_{g r}=P-\left(P_{h}+P_{z}+P_{L}\right),
$$


where $P_{h}$ is the power required to transport mined material to place of discharge; $P_{z}$ is the power needed to rotate the bucket wheel when empty; $P_{L}$ is the power needed to overcome friction between soil and bucket wheel ring (for cell-less and combined bucket wheels only).

The drive power of BWE SchRs 1320 consists of two Siemens ARNR 630Y-6 motors. Input power of both motors is measured. Motor power $P$ is then obtained from the equation:

$$
P=P_{p} \cdot \eta_{m} \cdot \cos \varphi_{m} \cdot \eta_{p},
$$

where $P_{p}$ is the sum of measured input power of both motors of bucket wheel; $\eta_{m}$ is the efficiency of electromotors; $\cos \varphi_{m}$ is the power factor of electromotors; $\eta_{p}$ is the efficiency of the gearbox of the bucket wheel.

Power $P_{h}$ for transport according to Durst and Vogt (1986) can be evaluated from Eq. (4). The significance of the equation is graphically illustrated in Fig. 2.

$$
P_{h}=\frac{F_{g F} \cdot h_{h}}{\eta_{h} \cdot t_{v}},
$$

where: $F_{g F}$ is the lifting force (see Fig. 2); $h_{h}$ is the median height of material lift; $\eta_{h}$ is the efficiency; $t_{v}$ is the rise time.
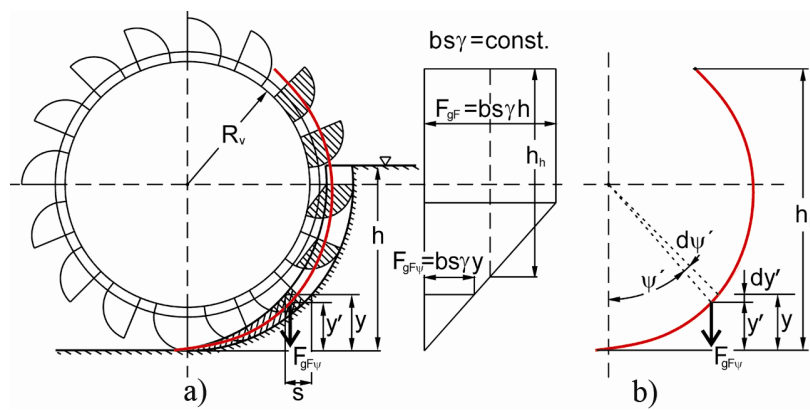

b)

Fig. 2. Scheme for evaluation of power $P_{h}$ (Durst, Vogt 1986)

The lifting force $F_{g F}$ is calculated according to Fig. 2 from the equation:

$$
F_{g F}=b \cdot s \cdot \gamma \cdot h,
$$

where $s$ is the cutting depth; $b$ the cutting width; $h$ the height of the terrace; $\gamma$ is the specific weight of the mined soil.

The rise time $t_{v}$ is calculated from parameters of the gearbox and measured revolutions of the motors of the bucket wheel. In this approach, little inaccuracies occur for the current structural arrangement of the motor of BWE SchRs 1320 because the rotations of the bucket wheel may be influenced by the inserted hydrodynamic fluid coupling Voith. Hydrodynamic fluid coupling is placed on the cardan shafts between the motor and gear box. The potential influence of this member in the system was neglected during analyses. The error obtained in such a manner is neglible for our purposes. The rise time $t_{v}$ is evaluated as follows:

$$
t_{v}=\frac{60 \cdot R}{n_{m} \cdot n_{b}},
$$

where $n_{m}$ is the average revolution of motors of the bucket wheel; $R$ is the gear ratio of gearbox of bucket wheel; $n_{b}$ is the number of buckets. In case of BWE SchRs $1320, R=172.05$ and $n_{b}=26$. The value of 60 in Eq. (6) means conversion to seconds because revolutions are measured per minutes.

Median lift height $h_{h}$ is calculated according to Fig. 2 using the equation:

$$
h_{h} \approx h_{E}-\frac{y_{\max }}{2},
$$

where height $y_{\max }$ is the value obtained from Eq. (9) for maximum angle $\psi_{\max }$ which is given by the equations:

For $\quad h<R_{k} ; \psi_{\max }=\arccos \frac{R_{k}-h}{R_{k}}$;

For

$$
h=R_{k} ; \psi_{\max }=90^{\circ} \text {; }
$$

For

$$
h>R_{k} ; \psi_{\max }=90^{\circ}+\arcsin \frac{h-R_{k}}{R_{k}} .
$$

Height $y_{\max }$ is calculated from the equation:

$$
y_{\text {max }}=R_{k}-\left(R_{k}-\frac{s}{2}\right) \cdot \cos \psi_{\text {max }} .
$$

The resulting total height of lift $h_{E}$ is determined in accordance with Fig. 2 from the equation:

$$
h_{E} \approx R_{k}+R_{v} \cdot \cos \left(180-\varphi_{v, 1}^{\prime}\right),
$$

where $R_{v}$ is the internal radius of the bucket wheel; $\varphi_{v, 1}^{\prime}$ is the angle at the start of soil emptying of the bucket wheel, which is obtained from the equation:

$$
\varphi_{v, 1}^{\prime}=\varphi_{v, 1}+\Delta \varphi,
$$

where angle $\varphi_{v, 1}$ is the start of bucket emptying for ideal soil (see Fig. 3). The angle $\Delta \varphi$ expresses the delay in emptying of bucket according to soil type (13). The angle $\varphi_{v, 1}$ is calculated according to Vladimirov et al. (1968):

$$
\varphi_{v, 1}=180^{\circ}-\arccos \frac{R_{v} \cdot \omega^{2}}{g} \pm \beta,
$$

where $\beta$ is the angle of tilt of the bucket wheel boom, and $g$ is acceleration due to gravity $9.81 \mathrm{~ms}^{-2}$.

Calculation of angle $\Delta \varphi$ is performed according to the work of Vladimirov et al. (1968). The overburden in Doly Nástup Tušimice consists mainly of clay which exhibits considerable block size during mining. In the course of evaluation, an approach based on the size of the block of mined overburden $a_{z}$ that is formed during mining is thus assumed. The following equation is considered:

$$
\Delta \varphi=2 \cdot \arcsin \frac{a_{z}}{2 \cdot R_{v} \cdot \cos \alpha_{v}},
$$

where $a_{z}$ is the so-called size of blocks of mined material, and angle $\alpha_{v}$ is calculated according to Vladimirov et al. (1968): 


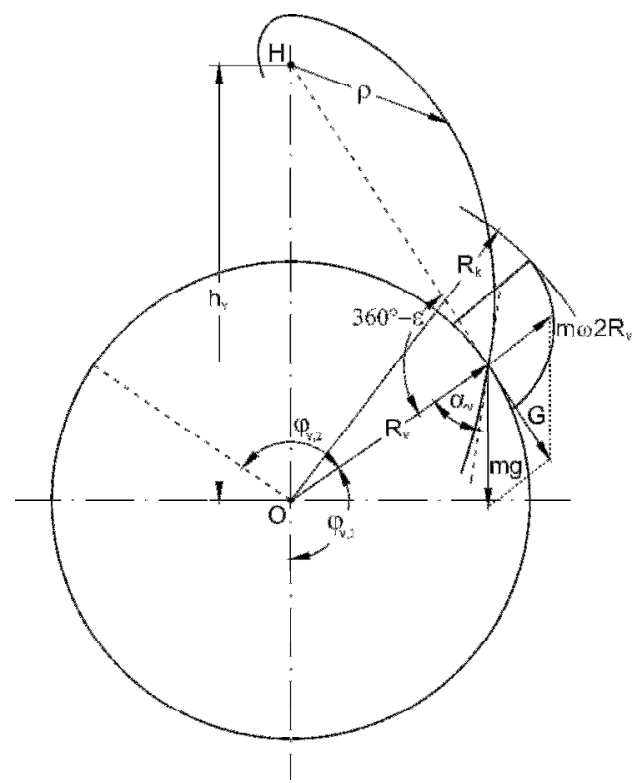

Fig. 3. Scheme of emptying of bucket (Vladimirov et al. 1968)

$$
\alpha_{v}=90^{\circ}-\arctan \left(\frac{R_{v} \cdot \omega^{2}}{g \cdot \sin \varphi_{v, 1}}+\tan \left(\varphi_{v, 1}\right)^{-1}\right)^{-1}+\varphi_{z},
$$

where $\varphi_{z}$ is the angle of repose of soil. The angular velocity of the bucket wheel is evaluated from measured revolutions of the bucket wheel motors. During evaluation, we commit the same error as it was in the case of the evaluation of rise time $t_{v}$. The resulting inaccuracy is negligible for our purposes. Calculation of angular velocity of the bucket wheel upon substitution of conversion constants for BWE SchRs 1320 can be expressed by the equation:

$$
\omega=\frac{2 \cdot \pi \cdot n_{m}}{n_{s} \cdot R} .
$$

The mutual relationship between angular velocity of the bucket wheel $\omega$ and tangential speed on the bucket cutting edge $v$ is given as:

$$
v=\omega \cdot R_{k} .
$$

The power $P_{z}$ of the motor for operation of the bucket wheel whilst empty was determined experimentally from measurements of the power of bucket wheel motors during its free rotation. The same conversion from equation (3) holds for the measured values. We can write:

$$
P_{Z}=P_{Z p} \cdot \eta_{m} \cdot \cos \varphi_{m} \cdot \eta_{p},
$$

where $P_{Z p}$ is the power of the motors of the bucket wheel measured during its free rotation.

Frictional power $P_{L}$ can be calculated according to the equation listed in (Durst et al. 1986). For measured cutting width $b$ and cutting depth $s$, we obtain the equation:

$$
P_{L}=s \cdot b \cdot h \cdot v \cdot \gamma \cdot f_{t},
$$

where $f_{t}$ is the coefficient of friction between the cutting wheel and soil.

\section{Measurements on the BWE}

During mining, a significant amount of operational data is measured on the BWE. The measured data are processed by the control computer in the BWE operator's cabin. Operational data are visually displayed to the operator of the excavator on monitors on the control panel. With the aid of these data, he is able to control the manner of mining, and check proper functionality of all parts of the excavator.

If necessary, the control computer can be set to save measured data to hard disk and utilize the measured data for offline processing. This option was used in the presented study. Saving of selected data was set for a period of approx. one month on the computer. Frequency of data logging was $1 \mathrm{~Hz}$ which was determined by the data bus line on BWE SchRs 1320. Measured data necessary for the study are listed in Table1.

Table 1. Measured values

\begin{tabular}{lc}
\hline \multicolumn{1}{c}{ Value } & Unit \\
\hline Input power of bucket wheel motor 2 & {$[\mathrm{~kW}]$} \\
Input power of bucket wheel motor 2 & {$[\mathrm{~kW}]$} \\
Revolutions of bucket wheel motor 1 & {$[\mathrm{rpm}]$} \\
Revolutions of bucket wheel motor 2 & {$[\mathrm{rpm}]$} \\
Horizontal position of bucket wheel boom & {$\left[{ }^{\circ}\right]$} \\
Vertical position of bucket wheel boom & {$\left[^{\circ}\right]$} \\
Distance moved by BWE & {$[\mathrm{m}]$} \\
\hline
\end{tabular}

The cutting width $b$ is evaluated from the measured horizontal position of the bucket wheel boom. The vertical position of the bucket wheel boom is used for the calculation of the height of the terrace $h$. The total block height is obtained from geodetic measurement. Records on the distance moved by the BWE are used to calculate the cutting depth $s$.

A mining record of a mining block of height of approx. $20.5 \mathrm{~m}$ was selected for the presented analysis. The working face was mined in four terraces. The first terrace had a height of $7.185 \mathrm{~m}$, second terrace a height of $5.084 \mathrm{~m}$, third terrace a height of $5.278 \mathrm{~m}$ and the fourth terrace was $3.172 \mathrm{~m}$ high. From the description, it is apparent that the terrace cutting method was used. This mining method is predominantly used in the Czech Republic. An illustration of the working face is shown in Fig. 4.

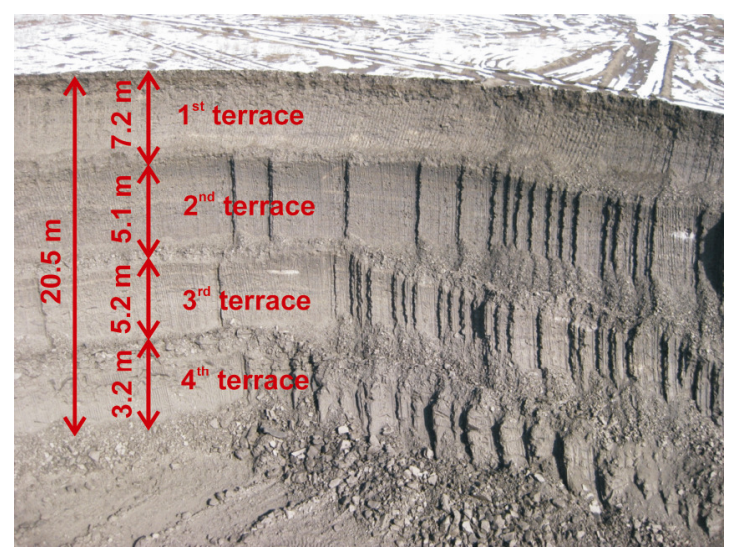

Fig. 4. Mining block during measurement 


\subsection{Statistical evaluation of measured variables}

Measured variables were divided into individual terraces during evaluation. Events not dealing directly with mining were filtered from the time course of data. They include, above all, excavator movement during change of terrace, and movements made during the cleaning of buckets. Thus, only data pertinent to standard mining using the terrace cutting method were evaluated. The statistical evaluation of measured variables for mining on the 1st terrace is described in the following text and figures of the present chapter.

The time course of averaged revolutions of bucket wheel motors is depicted in Fig. 5. Statistical evaluation yielded a histogram which we approximated using the Gauss probability density function, see Fig. 6 .

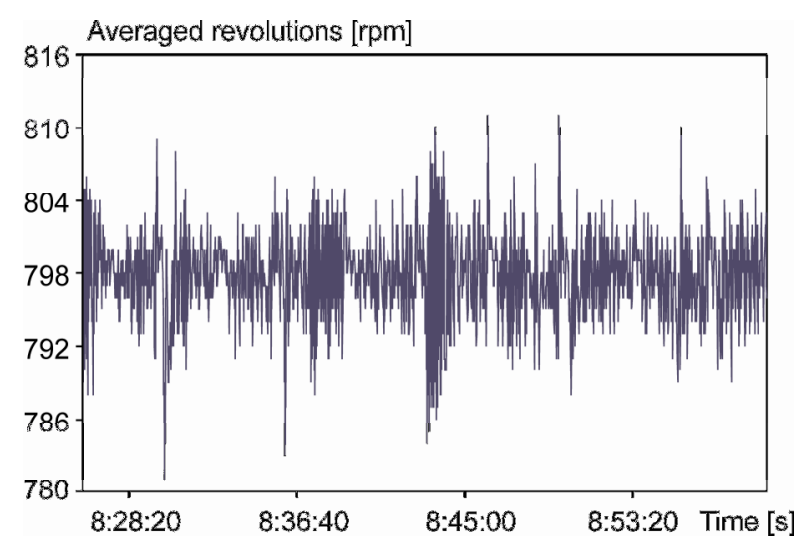

Fig. 5. Averaged revolutions of bucket wheel motors vs. mining time

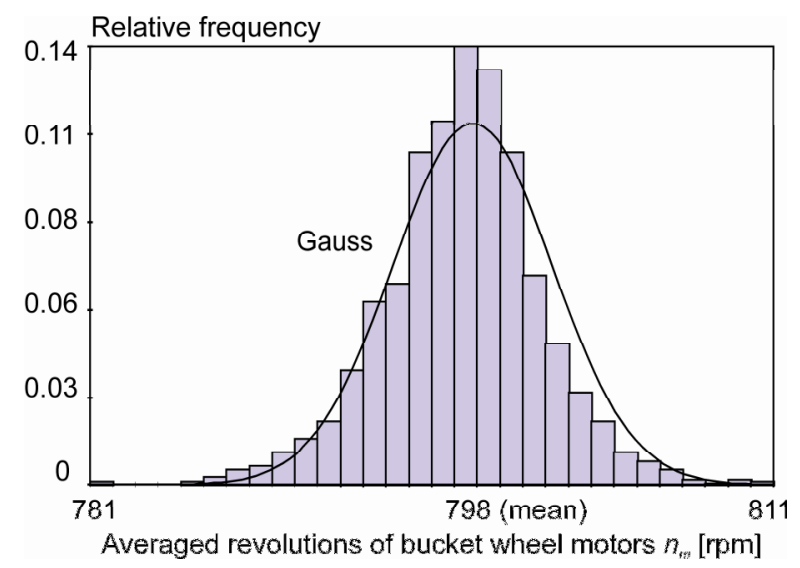

Fig. 6. Histogram of revolutions of bucket wheel motors

Fig. 7 illustrates the time course of the sum of input powers of bucket wheel motors. Regular decrease of input power of bucket wheel motors, which is given by retraction from the bench during change in the direction of rotation of the bucket wheel boom, is apparent in the Fig. 7. This phenomen was filtered off during evaluation, in order to avoid distortion of the histogram of input power of the bucket wheel motors in the mining process during the calculation of tangential digging force. The filtered time course of input power of bucket wheel

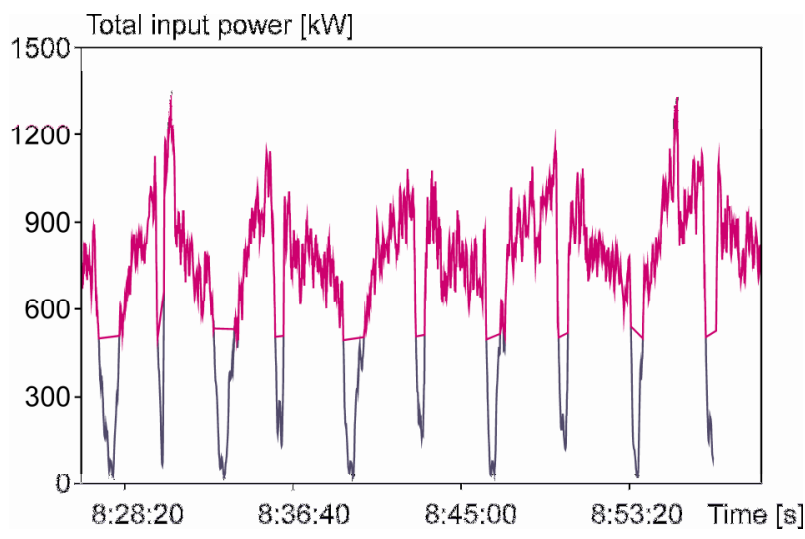

Fig. 7. Total input power of bucket wheel motors vs. mining time

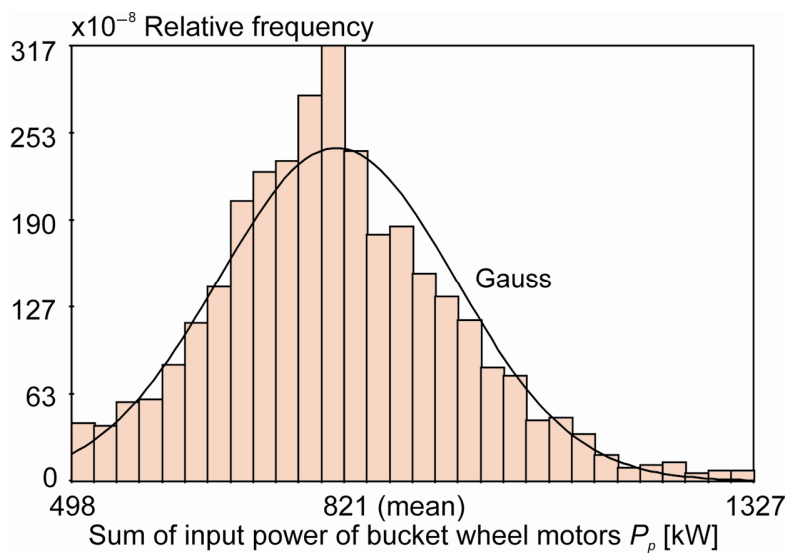

Fig. 8. Histogram of total input power of bucket wheel motors

motors is depicted in purple in Fig. 7. The Gauss probability density function was used once again for approximation; see Fig. 8 .

The cutting width was calculated from the measured horizontal position of the bucket wheel boom. The time course of the cutting width is depicted in Fig. 9. The mined terrace has the shape of a sickle, i.e., cutting depth decreases at its borders. In order to maintain maximum efficiency of mining, the speed of rotation is regulated, thus increasing or decreasing the cutting width. Ideally, the aim is for the ratio of $s / b$ to be constant during mining (Durst, Vogt 1986; Fries et al. 2010). The cutting width is thus a variable, see Fig. 9. Decrease of the value of the cutting width to zero is due to change of direction of rotation of the bucket wheel boom. Statistical evaluation of the cutting width is difficult due to its physical significance. The obtained histogram is depicted in Fig. 10, approximation was performed using the Gauss probability distribution after taking into account the geometry of the mining block.

The basic cutting depth is calculated from the record of advanced meters of the crawler tracks of the BWE. The BWE moves in steps during mining using the terrace cutting method where each step characterizes the digging of the excavator into the working face which corresponds to the cutting depth. The cutting depth is dependent on the horizontal position of the bucket wheel boom. The cutting depth decreases and increases according to the 
character of the sickle-form terrace. The recalculated time record of the cutting depth is depicted in Fig. 11. Rotation of the bucket wheel boom is apparent from the Fig. 11 where one arc corresponds to one slice on terrace. Statistical evaluation of such an event is very challenging. Hermite probability density function, which is the Gaussian probability density function multiplied by the Hermite polynom with respected skewness and kurtosis (programme Statrel 3.10), was used to approximate the histogram depicted in Fig. 12.

Cutting width $b[\mathrm{~m}]$

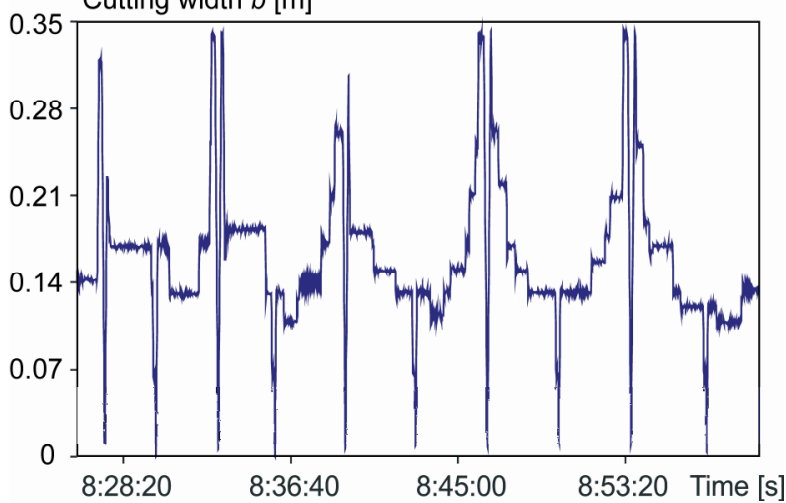

Fig. 9. Cutting width $b$ vs. mining time

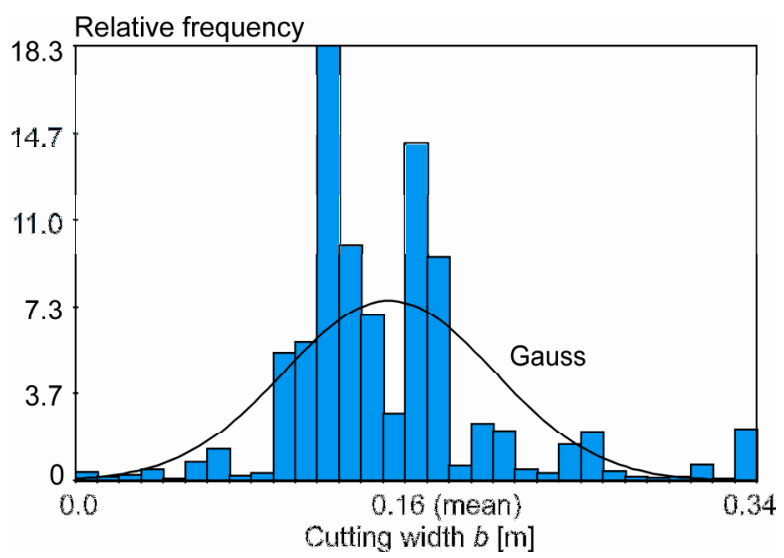

Fig. 10. Histogram of cutting width $b$

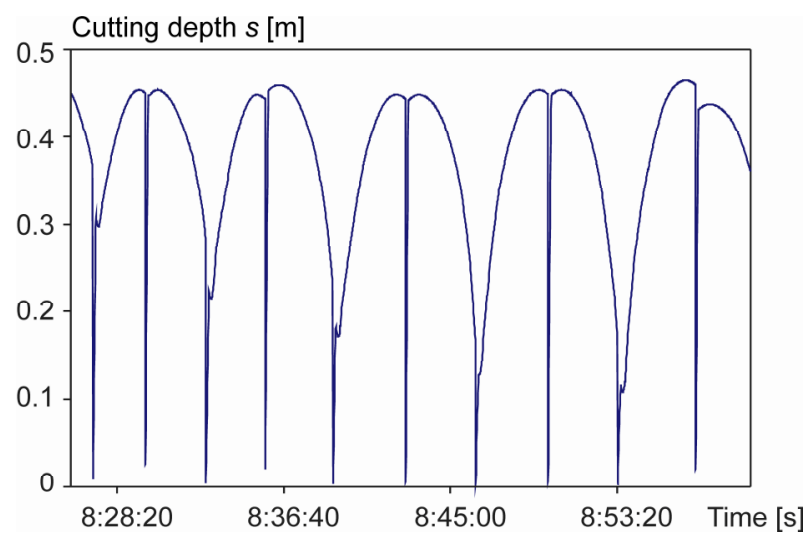

Fig. 11. Cutting depth $s$ vs. mining time

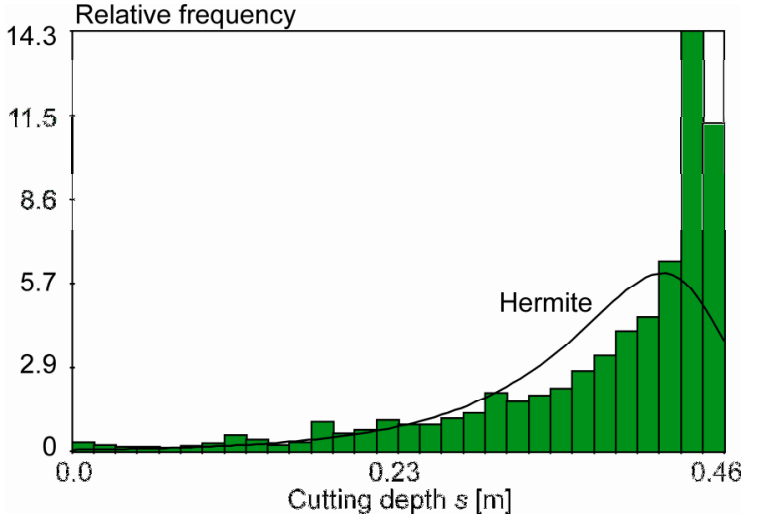

Fig. 12. Histogram of cutting depth $s$

The input power of bucket wheel motors during free rotation was measured for the determination of the power of the motor for operation of the bucket wheel whilst empty. Regulation of the revolution of the bucket wheel within $80 \%$ to $100 \%$ of the nominal revolution can be performed for the current configuration of the drive power of the bucket wheel with hydrodynamic fluid coupling Voith. This option is used during mining of clayey soil when the revolutions are decreased to the bottom limit of $80 \%$. The power $P_{Z p}$ was determined for two cases: $100 \%$ and $80 \%$ of nominal revolutions of bucket wheel motors. These measurements were performed during the whole series of measurements of individual movements of BWE SchRs 1320, see (Gottvald 2011). Mining had to be interrupted during measurements. Lengths of individual measurements were therefore minimized according to permissions from operational control. Due to this, the time record of measurements is approx. 1.5 minutes long in both cases. Approximately 90 values were measured within this time interval during sampling frequency of $1 \mathrm{~Hz}$ which is used for BWE SchRs 1320. It thus follows that the statistical evaluation is not entirely optimal. A uniform distribution was therefore chosen for approximation; see its statistical characteristics in Tables 2 to 5 . Sensitivity analysis results generally depend more on the selected ranges than on the assigned distribution (Saltelli et al. 2004; Arwade et al. 2010).

Fig. 5 shows that the mean value of revolutions of bucket wheel motors during mining of the first terrace is approx. equal to $800 \mathrm{rpm}$. This value corresponds to the level of $80 \%$ of nominal revolutions of bucket wheel motors. For the remaining terraces, the motors were at $100 \%$ of nominal revolutions. Descriptive characteristics of selected distributions are listed in Tables 2 to 5 , where Table 2 lists results for the first terrace, Table 3 lists the results for the second terrace, Table 4 lists the results for the third terrace, and Table 5 lists the results for the fourth terrace. The statistical characteristics of probability density functions that characterize variables $\varphi_{z}, a_{z}$ and $\gamma$ are also listed in the Tables 2 to 5 . These variables were evaluated from additional measurements performed during power testing of BWE SchRs 1320, (see Gottvald 2011). 
Table 2. Random variables for the first terrace

\begin{tabular}{ccccc}
\hline Symbol & Unit & Distribution & Mean value & $\begin{array}{c}\text { Std. } \\
\text { deviation }\end{array}$ \\
\hline$n_{m}$ & {$[\mathrm{rpm}]$} & Gauss & 797.799 & 3.498 \\
$P_{p}$ & {$[\mathrm{~W}]$} & Gauss & 820641 & 143621 \\
$P_{Z p}$ & {$[\mathrm{~W}]$} & Uniform & 49500 & 6639.53 \\
$b$ & {$[\mathrm{~m}]$} & Gauss & 0.158 & 0.053 \\
$\varphi_{z}$ & {$\left[{ }^{\circ}\right]$} & Uniform & 30 & 5.77 \\
$\gamma$ & {$\left[{\left.\mathrm{N} . \mathrm{m}^{-3}\right]}\right]$} & Gauss & 19559 & 875.77 \\
$a_{z}$ & {$[\mathrm{~m}]$} & Lognormal & 0.4 & 0.15 \\
$s$ & {$[\mathrm{~m}]$} & Hermite & 0.377 & 0.094 \\
& & & Skewness & Kurtosis \\
& & & -1.66 & 5.44 \\
\hline
\end{tabular}

Table 3. Random variables for the second terrace

\begin{tabular}{ccccc}
\hline Symbol & Unit & Distribution & Mean value & $\begin{array}{c}\text { Std. } \\
\text { deviation }\end{array}$ \\
\hline$n_{m}$ & {$[\mathrm{rpm}]$} & Gauss & 978.733 & 4.536 \\
$P_{p}$ & {$[\mathrm{~W}]$} & Gauss & 1227430 & 151649 \\
$P_{Z p}$ & {$[\mathrm{~W}]$} & Uniform & 75500 & 18186.5 \\
$b$ & {$[\mathrm{~m}]$} & Gauss & 0.155 & 0.047 \\
$\varphi_{z}$ & {$\left[{ }^{\circ}\right]$} & Uniform & 30 & 5.77 \\
$\gamma$ & {$\left[\mathrm{N}^{-3}\right]$} & Gauss & 19559 & 875.77 \\
$a_{z}$ & {$\left[\mathrm{~m}^{-3}\right]$} & Lognormal & 0.4 & 0.15 \\
$s$ & {$[\mathrm{~m}]$} & Hermite & 0.506 & 0.138 \\
& & & Skewness & Kurtosis \\
& & & -1.224 & 3.445 \\
\hline
\end{tabular}

Table 4. Random variables for the third terrace

\begin{tabular}{ccccc}
\hline Symbol & Unit & Distribution & Mean value & $\begin{array}{c}\text { Std. } \\
\text { deviation }\end{array}$ \\
\hline$n_{m}$ & {$[\mathrm{rpm}]$} & Gauss & 997.694 & 10.890 \\
$P_{p}$ & {$[\mathrm{~W}]$} & Gauss & 1244370 & 219840 \\
$P_{Z p}$ & {$[\mathrm{~W}]$} & Uniform & 75500 & 18186.5 \\
$b$ & {$[\mathrm{~m}]$} & Gauss & 0.185 & 0.052 \\
$\varphi_{z}$ & {$\left[{ }^{\circ}\right]$} & Uniform & 30 & 5.774 \\
$\gamma$ & {$\left[{\left.\mathrm{N} . \mathrm{m}^{-3}\right]}\right]$} & Gauss & 19559 & 875.77 \\
$a_{z}$ & {$[\mathrm{~m}]$} & Lognormal & 0.4 & 0.15 \\
$s$ & {$[\mathrm{~m}]$} & Hermite & 0.367 & 0.104 \\
& & & Skewness & Kurtosis \\
& & & -1.860 & 6.929 \\
\hline
\end{tabular}

Table 5. Random variables for the fourth terrace

\begin{tabular}{ccccc}
\hline Symbol & Unit & Distribution & Mean value & $\begin{array}{c}\text { Std. } \\
\text { deviation }\end{array}$ \\
\hline$n_{m}$ & {$[\mathrm{rpm}]$} & Gauss & 997.46 & 10.74 \\
$P_{p}$ & {$[\mathrm{~W}]$} & Gauss & 1313200 & 223770 \\
$P_{Z p}$ & {$[\mathrm{~W}]$} & Uniform & 75500 & 18186.5 \\
$b$ & {$[\mathrm{~m}]$} & Gauss & 0.148 & 0.041 \\
$\varphi_{z}$ & {$\left[{ }^{\circ}\right]$} & Uniform & 30 & 5.773 \\
$\gamma$ & {$\left[\mathrm{N}^{-3}\right]$} & Gauss & 19559 & 875.77 \\
$a_{z}$ & {$[\mathrm{~m}]$} & Lognormal & 0.4 & 0.15 \\
$s$ & {$[\mathrm{~m}]$} & Hermite & 0.587 & 0.174 \\
& & & Skewness & Kurtosis \\
& & & -1.826 & 6.098 \\
\hline
\end{tabular}

\subsection{Other input variables}

Deterministic (non-random) variables are present in the above described calculation of the tangential digging forces $F_{\text {grges }}$. Their constant values are listed in Table 6 .
Table 6. Constant variables for SchRs 1320

\begin{tabular}{ccc}
\hline Symbol & Value & Unit \\
\hline$\eta_{\text {grges }}$ & 90 & {$[\%]$} \\
$\eta_{m}$ & 96.5 & {$[\%]$} \\
$\eta_{p}$ & 95 & {$[\%]$} \\
$\eta_{h}$ & 90 & {$[\%]$} \\
$\cos \varphi_{m}$ & 0.85 & {$[-]$} \\
$f$ & 0.5 & {$[-]$} \\
$R_{k}$ & 6.25 & {$[\mathrm{~m}]$} \\
$R_{v}$ & 5.45 & {$[\mathrm{~m}]$} \\
$g$ & 9.81 & {$\left[\mathrm{~m} . \mathrm{s}^{-2}\right]$} \\
\hline
\end{tabular}

The terrace height $h$ and angle of tilt of the bucket wheel boom $\beta$ are variables that are fixed for each terrace always at the beginning of minig. Values of these variables are thus always chosen at the beginning, and remain unchanged during mining of the terrace. The variables are therefore non-random. Variables which correspond to the evaluated mining are listed in Table 7.

Table 7. Constant variables for SchRs 1320

\begin{tabular}{ccc}
\hline Terrace & $h[\mathrm{~m}]$ & $\beta\left[^{\circ}\right]$ \\
\hline First & 7.185 & 3.972 \\
Second & 5.084 & -2.866 \\
Third & 5.278 & -9.707 \\
Fourth & 3.172 & -14.900 \\
\hline
\end{tabular}

\section{Sensitivity analysis}

The sensitivity analysis studies the relationships between information flowing in and out of the model (Saltelli et al. 2004). Sensitivity analysis, within the scope of modelling, means different things to different people (see, e.g., Ferreira 2010; Mang et al. 2011; Keitel et al. 2011; Vaitkus 2011; Zhou et al. 2011). The basic measure of sensitivity is given by Spearman rank-order correlation (Kala 2005; Idoro 2012; Rafiei et al. 2012). The Sobol decomposition is an advanced method for the so-called global sensitivity analysis (Sobol 1993). One of the advantages of Sobol sensitivity analysis is that it enables the identification of interaction effects among input quantities (e.g. imperfections) on the monitored output (Kala 2009, 2011a, b, 2012).

\subsection{Sobol sensitivity analysis}

The coherent concept of sensitivity analysis enabling an analysis of the influence of arbitrary subgroups of input factors (doubles, triples, etc.) on the monitored output was elaborated by (Sobol 1993). Sobol sensitivity analysis was applied to analyze the influence of input variables $X_{i}$ (input quantities) on the tangential digging force $F_{\text {grges }}$ (output quantity $Y$ ) in the presented article.

The sensitivity coefficient of the first order for Sobol analysis may be written as:

$$
S_{i}=\frac{V\left(E\left(Y \mid X_{i}\right)\right)}{V(Y)} .
$$


Sobol proposed an alternate definition $S_{\mathrm{i}}=\operatorname{corr}\left(Y, E\left(Y \mid X_{\mathrm{i}}\right)\right)$ which is based on the calculation of the correlation between output random variable $Y$ and conditional random arithmetical mean $E\left(Y \mid X_{\mathrm{i}}\right)$. Analogously as in (19), we can write the second order coefficient as:

$$
S_{i j}=\frac{V\left(E\left(Y \mid X_{i}, X_{j}\right)\right)}{V(Y)}-S_{i}-S_{j} .
$$

Sensitivity coefficient $S_{i j}$ expresses the influence of doubles on the monitored output. In a similar manner, we can write other Sobol sensitivity coefficients enabling the quantification of higher order interactions.

The advanced Monte Carlo method was applied (Vořechovský, Novák 2009; Vořechovský 2012). The case with statistically independent input random variables $X_{i}$ was studied. The variance $V(Y)$ of tangential digging force is calculated under the assumption that all input variables are considered as random; one million simulation runs were applied. The conditional random arithmetical mean $E\left(Y \mid X_{\mathrm{i}}\right)$ was evaluated for $N=30000$ simulation runs; the variance $V\left(E\left(Y \mid X_{i}\right)\right)$ was calculated for $N=30000$ simulation runs as well, i.e., the numerical demanding difficulty of the calculation is $N^{2}$. The procedure was similar for the calculation of the second order indices (20).

Decomposition of Sobol sensitivity coefficients can be written as:

$$
\sum_{i} S_{i}+\sum_{i} \sum_{j>i} S_{i j}+\sum_{i} \sum_{j>i} \sum_{k>j} S_{i j k}+\ldots+S_{123 \ldots M}=1 .
$$

The number of members in (21) is $2^{M}-1$, i.e., for $M=3$, we obtain 7 sensitivity coefficients $S_{1}, S_{2}, S_{3}, S_{12}$, $S_{23}, S_{13}, S_{123}$; for $M=8$, we obtain 255 sensitivity coefficients, which is too much for practical application. The main obstacle in the determination of all members (21) is the high numerical demand of their calculation.

\subsection{Sensitivity analysis results}

Results of sensitivity analyses of the tangential digging force for the first terrace are depicted in Fig. 13. Results for the second terrace are shown in Fig. 14 and obtained results for the third and fourth terraces are shown in Fig. 15 and Fig. 16 respectively. The presented approach in the calculation of the total tangential digging force is based on the knowledge of the input powers of the bucket wheel motors, which can be measured easily. One could say that it is the inverse method of the calculation of the total tangential digging force $F_{\text {grges }}$, because the measured input power of bucket wheel motors $P_{p}$ is in reality the reaction to the tangential digging force, i.e., the size of the input power of bucket wheel motors is dependent on the size of the total tangential digging force. It is apparent from the graphs in Figs 13 to 16 that the input power $P_{p}$ of the bucket wheel motors has the greatest influence on the size of the total tangential digging force $F_{\text {grges }}$ for the selected approach in the calculation. According to the physical essence of the mining process, the input power of the bucket wheel motors is, in reality, a reaction to the total tangential digging force.

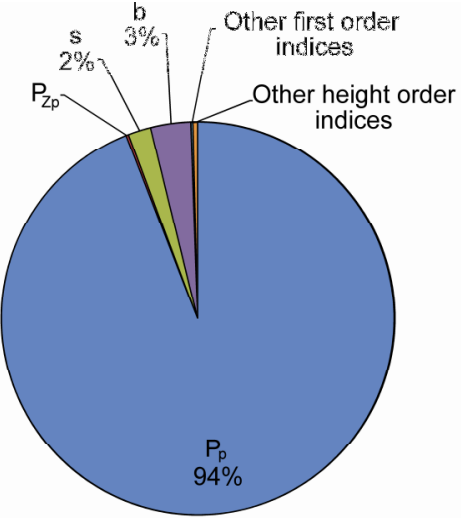

Fig. 13. Results for the first terrace

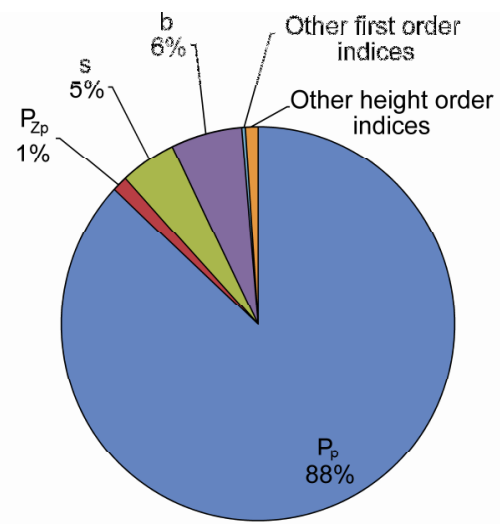

Fig. 14. Results for the second terrace

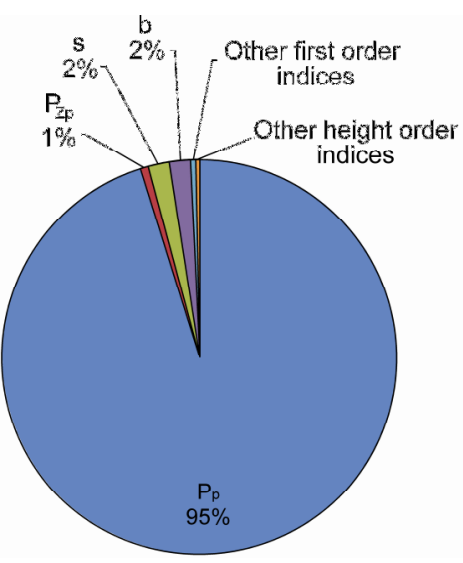

Fig. 15. Results for the third terrace

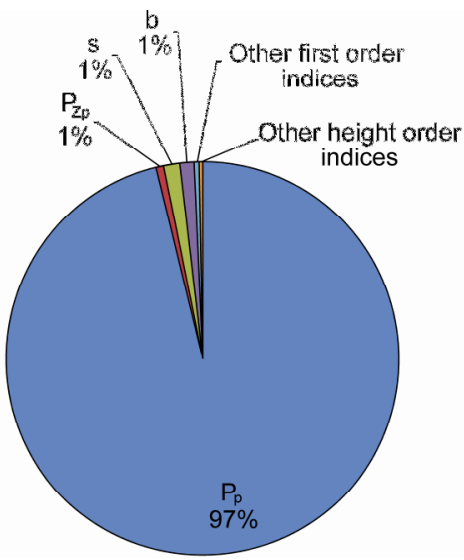

Fig. 16. Results for the fourth terrace 
The percentual representation of the input power of bucket wheel motors $P_{p}$ is significant in all cases, and that leads to a less accurate description (overlap) of the influence of other random variables. Therefore, other sensitivity analyses were performed with the input power of the bucket wheel motors considered as a non-random value which was determined as the mean value of a priori considered random variables. The influences of the other quantities on the total tangential digging force is more evident from the rendered graphs. Results for the first terrace are shown in Fig. 17, for the second terrace in Fig. 18, for the third terrace in Fig. 19 and for the fourth terrace in Fig. 20.

The significantly changing effect of the cutting width $b$ on the size of the total tangential digging force $F_{\text {grges }}$ is apparent from the results. The effect is $57 \%$ in the first terrace, and it decreases up to $32 \%$ in the fourth terrace. On the contrary, the effect of the revolutions of bucket wheel motors $n_{m}$ increases (from $1 \%$ in the first terrace to $10 \%$ in the fourth terrace) as does the input power of the bucket wheel motors during free rotation $P_{Z p}$ (from $4 \%$ in the first terrace till $17 \%$ in the fourth terrace). The effect of the cutting depth $s$ is $33 \%$ in the first terrace and from the second terrace, it has a constant value of $37 \%$. It is important to note that the first terrace was mined with less revolutions of the bucket wheel, respectively bucket wheel motors than the other terraces. Analyses further showed that the effects of high order interactions of input random variables on the total tangential digging force were practically negligible. Let us note that each calculation was performed for the height of the terrace corresponding to conditions during measurement, see Table 7.

Analyses considering same terrace heights for all cases were performed in order to enable better comparison of results. The following terrace heights were gradually considered: $3,4,5,6$ and $7 \mathrm{~m}$. During the determination of the trend of sensitivity, we also focused only on the following variables:

- Average revolution of bucket wheel motors $n_{m}$, see Fig. 21;

- Input power of bucket wheel motor during free rotation $P_{Z p}$, see Fig. 22;

- Cutting depth $s$, see Fig. 23;

- Cutting width $b$, see Fig. 24.

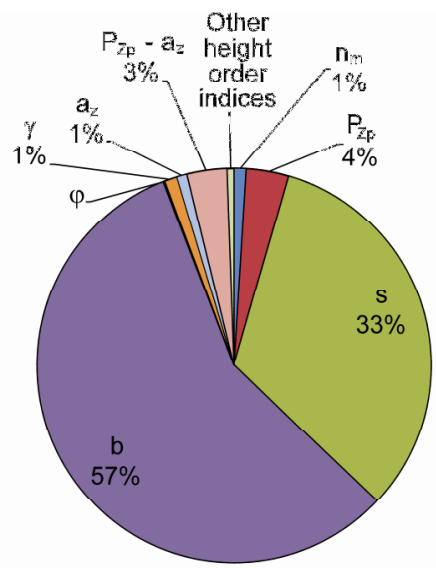

Fig. 17. Results for the first terrace $\left(P_{p}\right.$ is a non-random variable)

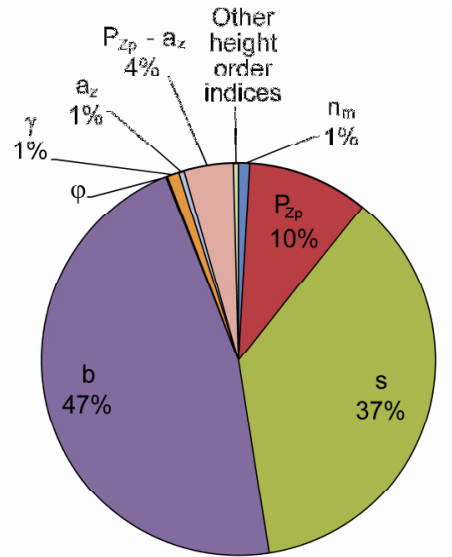

Fig. 18. Results for the second terrace $\left(P_{p}\right.$ is a non-random variable)

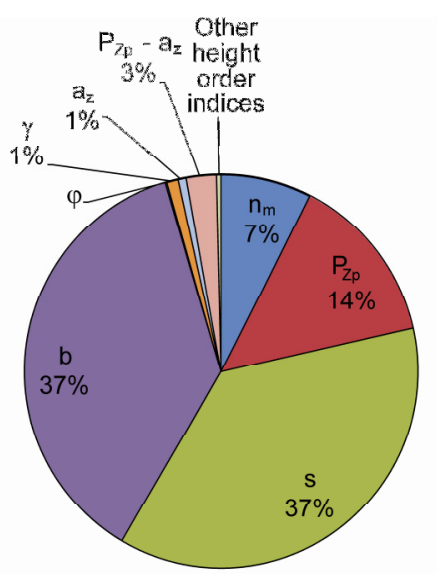

Fig. 19. Results for the third terrace $\left(P_{p}\right.$ is a non-random variable)

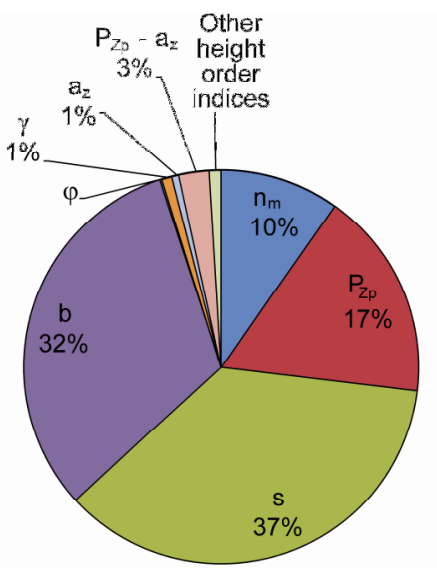

Fig. 20. Results for the fourth terrace $\left(P_{p}\right.$ is a non-random variable)

In the following graphs, the terrace heights are plotted on the horizontal axes, and the effects in percentages of experimentally obtained random variables on the total tangential digging force are plotted on the vertical axes. Results where the input power of bucket wheel motors was considered as a non-random value are plotted in the graphs. 


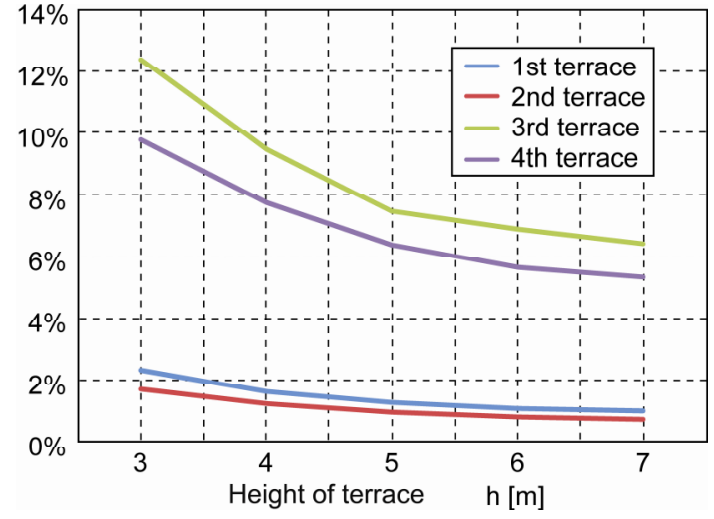

Fig. 21. Trend of change of effect of revolutions of motor $n_{m}$

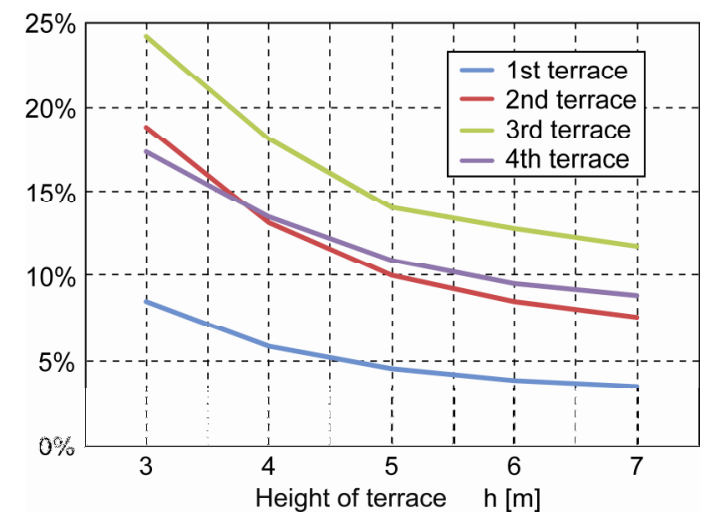

Fig. 22. Trend of change of effect of input power of motors during free rotation of the bucket wheel $P_{Z p}$

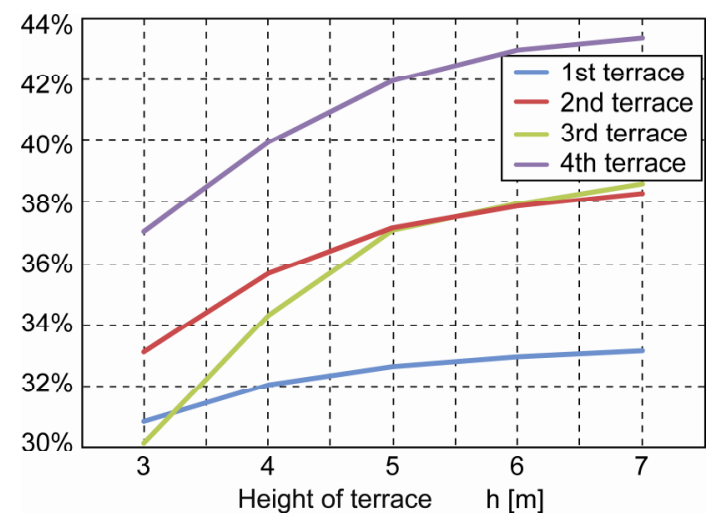

Fig. 23. Trend of change of effect of cutting depth $s$

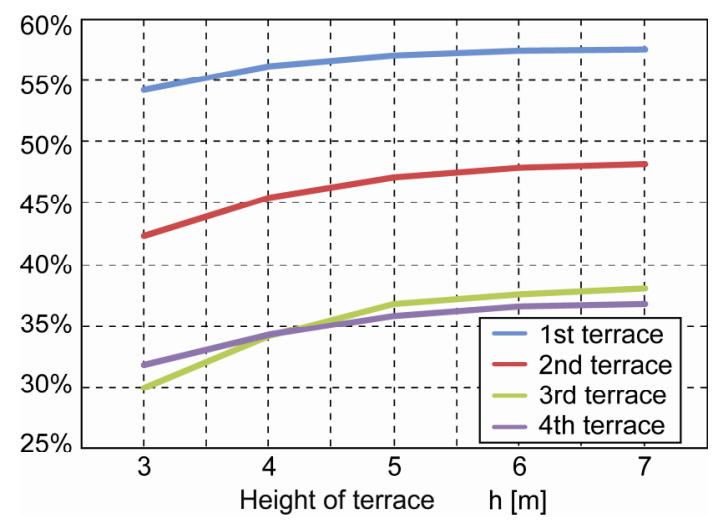

Fig. 24. Trend of change of effect of cutting width $b$
The effect of individual variables on the size of the total tangential digging force in respective terraces is apparent from the resulting graphs. Sobol sensitivity coefficients of cutting width and cutting depth increase with terrace height. This trend is identical for the analysis of inputs from all four terraces. On the contrary, Sobol sensitivity coefficients of revolutions of motors and input power of the motors during free rotation of the bucket wheel decrease with terrace height.

\section{Conclusions}

The aim of the sensitivity analysis was to determine the effect of experimentally determined random variables on the total tangential digging force. This effect was quantified using Sobol sensitivity coefficients.

For the adopted calculation method of the tangential digging force, the percentage of the effect of the input power of the motors of the bucket wheel is substantial, it is $94 \%$ for the first terrace, $88 \%$ for the second terrace, $95 \%$ for the third terrace, and $97 \%$ for the fourth terrace.

The variability of the input power of the bucket wheel motors overlaps the effects of other random variables. It was therefore considered in further studies as a nonrandom value which was obtained as the mean value of a priori considered random variables. The varying effect of the cutting width and the relatively unvarying effect of the cutting depth, where the first variable is within the interval of $32-57 \%$ and the second one, in the interval of $33-37 \%$, can be observed in the obtained results. This fact points to considerable inefficiency of mining process. It is known from comprehensive studies (Durst, Vogt 1986) that the optional dimensions of the mining block are influenced by the intensity of digging force, but, in particular, by the efficiency of mining. For the maximum efficiency of mining, it is necessary to maintain the constant horizontal area of the mining block. Thus, it is necessary to maintain the fixed ratio of two variable parameters, namely of the cutting depth and cutting width, i.e., $s / b=$ constant. It follows from the results that, in particular in case of the first terrace which was mined, rotations of the bucket wheel being different from those in the other terraces, the percentual proportion of the variance effect is considerably different for both quantities.

In subsequential steps of the sensitivity analysis, the change of the effect of random variables on the tangential digging force on all four terraces for different terrace heights $3 \mathrm{~m}, 4 \mathrm{~m}, 5 \mathrm{~m}, 6 \mathrm{~m}$ and $7 \mathrm{~m}$ were examined. Based on the results obtained from analysis, we can state that the effect of the revolution of the motors of the bucket wheel on the tangential digging force significantly increases for the third and fourth terraces and their effect is enhanced by decrease in terrace height. The effect of the input powers of the bucket wheel motors during free rotation of the bucket wheel has a similar character. Neither position of the terrace nor height of the terrace has an effect on a significant change in the effect of cutting depth. Change in the effect of the cutting width uniformly decreases from the first to the fourth terrace. Change in terrace height has not significant effect on its influence. This knowledge can be used to determine the 
optimum of the terrace height, the optimum mining effectiveness, and loading of mining equipment.

Sensitivity analyses further show that the higher order interaction effects of input random variables on the tangential digging force are practically negligible.

\section{Acknowledgement}

The authors gratefully acknowledge the financial support provided by the Czech Ministry of Industry and Trade within the project FR-TI1/086 and the financial support of the European Union's "Operational Programme Research and Development for Innovations", No. CZ.1.05/2.1.00/ 03.0097, as an activity of the regional Centre AdMaS "Advanced Materials, Structures and Technologies".

\section{References}

Amšiejus, J.; Dirgėlienė, N.; Norkus, A.; Žilionienė, D. 2009. Evaluation of soil shear strength parameters via triaxial testing by height versus diameter ratio of sample, The Baltic Journal of Road and Bridge Engineering 4(2): 55-60.

Amšiejus, J.; Kačianauskas, R.; Norkus, A.; Tumonis, L. 2010. Investigation of the sand porosity via oedometric testing, The Baltic Journal of Road and Bridge Engineering 5(3): 139-147. http://dx.doi.org/10.3846/bjrbe.2010.20

Arwade, S. R.; Moradi, M.; Louhghalam, A. 2010. Variance decomposition and global sensitivity for structural systems, Engineering Structures 32(1): 1-10. http://dx.doi.org/10.1016/j.engstruct.2009.08.011

Bošnjak, S.; Petković, Z.; Zrnić, N.; Simić, G.; Simonović, A. 2009a. Cracks, repair and reconstruction of bucket wheel excavator slewing platform, Engineering Failure Analysis 16(5): 1631-1642.

http://dx.doi.org/10.1016/j.engfailanal.2008.11.009

Bošnjak, S.; Zrnić, N.; Simonović, A.; Momčilović, D. 2009b. Failure analysis of the end eye connection of the bucket wheel excavator portal tie-rod support, Engineering Failure Analysis 16(3): 740-750.

http://dx.doi.org/10.1016/j.engfailanal.2008.06.006

Bošnjak, S.; Petković, Z.; Zrnić, N.; Pantelić, M.; Obradović, A. 2010. Failure analysis and redesign of the bucket wheel excavator two-wheel bogie, Engineering Failure Analysis 17(2): 473-485.

http://dx.doi.org/10.1016/j.engfailanal.2009.09.007

Bošnjak, S. M.; Arsić, M. A.; Zrnić, N.; Rakin, M.; Pantelić, M. 2011. Bucket wheel excavator integrity assessment of the bucket wheel boom tie-rod welded joint, Engineering Failure Analysis 18(1): 212-222. http://dx.doi.org/10.1016/j.engfailanal.2010.09.001

Durst, W.; Vogt, W. 1986. Schaufelrad Bagger [Bucket wheel excavators]. Clausthal-Zellerfeld. $375 \mathrm{p}$.

Ferreira, R. M. 2010. Implications on RC structure performance of model parameter sensitivity: Effect of chlorides, Journal of Civil Engineering and Management 16(4): 561-566. http://dx.doi.org/10.3846/jcem.2010.62

Fries, J.; Gottvald, J.; Helebrant, F.; Jurman, J.; Vejvoda, S. 2010. Vybraná problematika z provozu kolesových rypadel [Selected problems from the operation of bucket wheel excavators]. Ostrava: Publishing Centre of Technical University of Ostrava. 210 p.

Gottvald, J. 2010. The calculation and measurement of the natural frequencies of the bucket wheel excavator SchRs 1320/4x30, Transport 25(3): 269-277.

http://dx.doi.org/10.3846/transport.2010.33
Gottvald, J. 2011. Experimentální a pravděpodobnostní analýza provozni spolehlivosti kolesového rypadla SchRs 1320/4x30 [Experimental and probabilistic analysis of operational reliability of the bucket wheel excavator SchRs 1320/4x30]. PhD. Thesis. Brno: Brno University of Technology. $205 \mathrm{p}$.

Idoro, G. I. 2012. Sustainability of mechanisation in the Nigerian construction industry, Journal of Civil Engineering and Management 18(1): 91-105. http://dx.doi.org/10.3846/13923730.2011.604541

Jiang, S.; Jang, W.-S.; Skibniewski, M. J. 2012. Selection of wireless technology for tracking construction materials using a fuzzy decision model, Journal of Civil Engineering and Management 18(1): 43-59. http://dx.doi.org/10.3846/13923730.2011.652157

Juozapaitis, A.; Idnurm, S.; Kaklauskas, G.; Idnurm, J.; Gribniak, V. 2010. Non-linear analysis of suspension bridges with flexible and rigid cables, Journal of Civil Engineering and Management 16(1): 149-154. http://dx.doi.org/10.3846/jcem.2010.14

Kala, Z. 2005. Sensitivity analysis of the stability problems of thin-walled structures, Journal of Constructional Steel Research 61(3): 415-422.

http://dx.doi.org/10.1016/j.jcsr.2004.08.005

Kala, Z. 2007. Stability problems of steel structures in the presence of stochastic and fuzzy uncertainty, Thin-Walled Structures 45(10-11): 861-865. http://dx.doi.org/10.1016/j.tws.2007.08.007

Kala, Z. 2008. Fuzzy probability analysis of the fatigue resistance of steel structural members under bending, Journal of Civil Engineering and Management 14(1): 6772. http://dx.doi.org/10.3846/1392-3730.2008.14.67-72

Kala, Z. 2009. Sensitivity assessment of steel members under compression, Engineering Structures 31(6): 1344-1348. http://dx.doi.org/10.1016/j.engstruct.2008.04.001

Kala, Z. 2011a. Sensitivity analysis of steel plane frames with initial imperfections, Engineering Structures 33(8): 23422349. http://dx.doi.org/10.1016/j.engstruct.2011.04.007

Kala, Z. 2011b. Sensitivity analysis of stability problems of steel plane frames, Thin-Walled Structures 49(5): 645651. http://dx.doi.org/10.1016/j.tws.2010.09.006

Kala, Z. 2012. Geometrically non-linear finite element reliability analysis of steel plane frames with initial imperfections, Journal of Civil Engineering and Management 18(1): 81-90. http://dx.doi.org/10.3846/13923730.2012.655306

Kala, Z.; Melcher, J.; Puklický, L. 2009. Material and geometrical characteristics of structural steels based on statistical analysis of metallurgical products, Journal of Civil Engineering and Management 15(3): 299-307. http://dx.doi.org/10.3846/1392-3730.2009.15.299-307

Kala, Z.; Puklický, L.; Omishore, A.; Karmazínová, M.; Melcher, J. 2010. Stability problems of steel-concrete members composed of high-strength materials, Journal of Civil Engineering and Management 16(3): 352-362. http://dx.doi.org/10.3846/jcem.2010.40

Karmazínová, M.; Melcher, J.; Kala, Z. 2009. Design of expansion anchors to concrete based on results of experimental verification, Advanced Steel Construction 5(4): 390-405.

Keitel, H.; Karaki, G.; Lahmer, T.; Nikulla, S.; Zabel, V. 2011. Evaluation of coupled partial models in structural engineering using graph theory and sensitivity analysis, Engineering Structures 33(12): 3726-3736. http://dx.doi.org/10.1016/j.engstruct.2011.08.009 
Kowal, Z. 2011. The formation of bar space structures supported by the system reliability theory, Archives of Civil and Mechanical Engineering 11(1): 115-133. http://dx.doi.org/10.1016/S1644-9665(12)60178-2

Králik, J.; Králik, J. 2009. Seismic analysis of reinforced concrete frame-wall systems considering ductility effects in accordance to Eurocode, Engineering Structures 31(12): 2865-2872. http://dx.doi.org/10.1016/j.engstruct.2009.07.029

Lashgari, A.; Fouladgar, M. M.; Yazdani-Chamzini, A.; Skibniewski, M. J. 2011. Using an integrated model for shaft sinking method selection, Journal of Civil Engineering and Management 17(4): 569-580.

http://dx.doi.org/10.3846/13923730.2011.628687

Liaudanskiene, R.; Simanaviciene, R.; Ustinovichius, L. 2012. A model for solving structural, technological and safety problems, Journal of Civil Engineering and Management 18(1): 30-42. http://dx.doi.org/10.3846/13923730.2011.643551

Radoń, U. 2011. Probabilistic nonlinear analysis of truss structure, Archives of Civil and Mechanical Engineering 11(3): 723-738.

Rafiei, K.; Kavussi, A.; Yasrobi, S. 2012. Construction quality control of unbound layers based on stiffness modulus criteria, Journal of Civil Engineering and Management 18(1): 5-13. http://dx.doi.org/10.3846/13923730.2011.619328

Rusiński, E.; Czmochowski, J.; Iluk, A.; Kowalczyk, M. 2010a. An analysis of the causes of a BWE counterweight boom support fracture, Engineering Failure Analysis 17(1): 179191. http://dx.doi.org/10.1016/j.engfailanal.2009.06.001

Rusiński, E.; Harnatkiewicz, P.; Kowalczyk, M.; Moczko, P. 2010b. Examination of the causes of a bucket wheel fracture in a bucket wheel excavator, Engineering Failure Analysis 17(6): 1300-1312.

http://dx.doi.org/10.1016/j.engfailanal.2010.03.004

Saltelli, A.; Chan, K.; Scott, E. M. 2004. Sensitivity analysis. Wiley series in probability and statistics, New York: John Wiley and Sons. $475 \mathrm{p}$.

Sandovič, G.; Juozapaitis, A.; Kliukas, R. 2011. Simplified engineering method of suspension two-span pedestrian steel bridges with flexible and rigid cables under action of asymmetrical loads, The Baltic Journal of Road and Bridge Engineering 6(4): 267-273.

http://dx.doi.org/10.3846/bjrbe.2011.34

Savković, M.; Gašić, M.; Arsić, M.; Petrović, R. 2011. Analysis of the axle fracture of the bucket wheel excavator, Engineering Failure Analysis 18(1): 433-441. http://dx.doi.org/10.1016/j.engfailanal.2010.09.031

Sobol, I. M. 1993. Sensitivity analysis for non-linear mathematical models, Mathematical Modelling and Computational Experiment 1: 407-414; Translated from Russian: I. M. Sobol'. 1990. Sensitivity estimates for nonlinear mathematical models, Matematicheskoe Modelirovanie 2: 112-118.

Sušinskas, S.; Zavadskas, E. K.; Turskis, Z. 2011. Multiple criteria assessment of pile-columns alternatives, The Baltic Journal of Road and Bridge Engineering 6(3): 77-83.
Torno, S.; Toraño, J.; Menéndez, M.; Gent, M.; Velasco, J. 2011. Mathematical and fuzzy logic models in prediction of geological and geomechanical properties of rock mass by excavation data on underground works, Journal of Civil Engineering and Management 17(2): 197-206.

Turskis, Z.; Gajzler, M.; Dziadosz, A. 2012. Reliability, risk management, and contingency of construction processes and projects, Journal of Civil Engineering and Management 18(2): 290-298.

http://dx.doi.org/10.3846/13923730.2012.672931

Mang, H. A.; Höfinger, G.; Jia, X. 2011. On the interdependency of primary and initial secondary equilibrium paths in sensitivity analysis of elastic structures, Computer Methods in Applied Mechanics and Engineering 200(13-16): 15581567. http://dx.doi.org/10.1016/j.cma.2010.12.025

Melcher, J.; Škaloud, M.; Kala, Z.; Karmazínová, M. 2009. Sensitivity and statistical analysis within the elaboration of steel plated girder resistance, Advanced Steel Construction 5(2): 120-126.

Melcher, J.; Kala, Z.; Holický, M.; Fajkus, M.; Rozlívka, L. 2004. Design characteristics of structural steels based on statistical analysis of metallurgical products, Journal of Constructional Steel Research 60(3-5): 795-808. http://dx.doi.org/10.1016/S0143-974X(03)00144-5

Vaitkus, L. 2011. Low charge transport refrigerator (I). Refrigerant charge and strategies of charge reduction, structures, Mechanika [Mechanics] 17(6): 665-673.

Venskus, A.; Kalanta, S.; Atkočiūnas, J.; Ulitinas, T. 2010. Integrated load optimization of elastic-plastic axisymmetric plates at shakedown, Journal of Civil Engineering and Management 16(2): 203-208. http://dx.doi.org/10.3846/jcem.2010.22

Vladimirov, V. M.; Shenderov, A. N.; Kalashnikov, Y. T.; Khazanet, L. L. 1968. Kar'ernye rotornye ekskavatory [Mining bucket wheel excavators]. Kyjev: Technika, 106 p.

Vořechovský, M.; Novák, D. 2009. Correlation control in smallsample Monte Carlo type simulations I: A simulated annealing approach, Probabilistic Engineering Mechanics 24(3): 452-462. http://dx.doi.org/10.1016/j.probengmech.2009.01.004

Vořechovský, M. 2012. Correlation control in small sample Monte Carlo type simulations II: Analysis of estimation formulas, random correlation and perfect uncorrelatedness, Probabilistic Engineering Mechanics 29: 105-120.

Zavadskas, E. K.; Turskis, Z.; Tamosaitiene, J. 2011. Selection of construction enterprises management strategy based on the SWOT and multi-criteria analysis, Archives of Civil and Mechanical Engineering 11(4): 1063-1082. http://dx.doi.org/10.1016/S1644-9665(12)60096-X

Zhou, Y.; Peng, F. Y.; Cao, X. H. 2011. Parameter sensitivity analysis of axial vibration for lead-screw feed drives with time-varying framework, Mechanika [Mechanics] 17(5): $523-528$

Jakub GOTTVALD. PhD, Head of steel structures and storage tanks department at VÍTKOVICE ÚAM Inc. A member of the Czech Society for Mechanics. The author and co-author of about 30 scientific papers. Research interests: applied mechanics, experimental and computational mechanics, FEM analyses of structures and results of in-situ measurement verifications.

Zdeněk KALA. Professor, PhD, Department of Structural Mechanics, Brno University of Technology, Faculty of Civil Engineering. Co-author of 14 books, 3 textbooks and more than 180 scientific papers (120 published abroad), Member of Czech Society for Mechanics. Research interests: elastic-plastic analysis, stability problems, sensitivity analysis and optimisation of steel and steelconcrete structures including material and geometrical nonlinearities, numerical methods in structural mechanics, reliability methods. 